\title{
ESRC-DFID Research for Policy and Practice:
}

\section{Urban community resilience}

March 2019

\section{Foreword}

C ities have the potential to be great drivers of improvements in human wellbeing. And yet, impoverishment is an unrelenting feature of urban life. Exclusionary, incomplete, or even speculative infrastructures mediate almost every aspect of people's everyday urban lives, even if the promise of agglomerated living includes everything from improved access to basic services such as electricity, water and sewerage, to affordable housing, health care and quality education. The very processes that enable dense conurbation also involve deeply unequal relationships of power running through systems of urban exchange. Addressing urban impoverishment is therefore as much an infrastructural challenge as it is a challenge requiring political and social transformation.

This collection of ESRC-DFID-funded research tackles such issues head on. Transdisciplinary research and policy consortia have come together to interrogate what makes cities inclusive, safe, resilient and sustainable in times when migration and urbanisation processes are intensifying globally. The studies articulate that the everyday lived realities of the most marginalised or least resourced urban residents matter, and are relevant to different scales of development and governance. 'Hyper local' issues ranging from women managing fuel scarcity in peri-urban Nigeria; to urban refugees advocating for access to front-line services in Chattogram, Bangladesh; and from the potential for sport, culture and education programmes to tackle poverty in Cape Verde; to residents' groups innovating to tackle property crime in the city of Kaduna, Nigeria, remain just as relevant to global advocacy around urban sustainability through the New Urban Agenda, the Sustainable Development Goals and the Intergovernmental Panel on Climate Change (IPCC).

It is of particular value that these studies break disciplinary silos and commit to South-South learning partnerships. This speaks directly to the collaborative ways of working and the iterative dialogue between research, policy, and action that are essential not only to understanding the complexities of the grand challenges of the twenty-first century, but also in seeking policy alternatives for enabling sustainable, resilient, and safe urban futures.

\section{Dr Jaideep Gupte}

Fellow, Institute of Development Studies and Challenge Leader, Cities and Sustainable Infrastructure Portfolio, Global Challenges Research Fund (GCRF), UK Research and Innovation (UKRI)

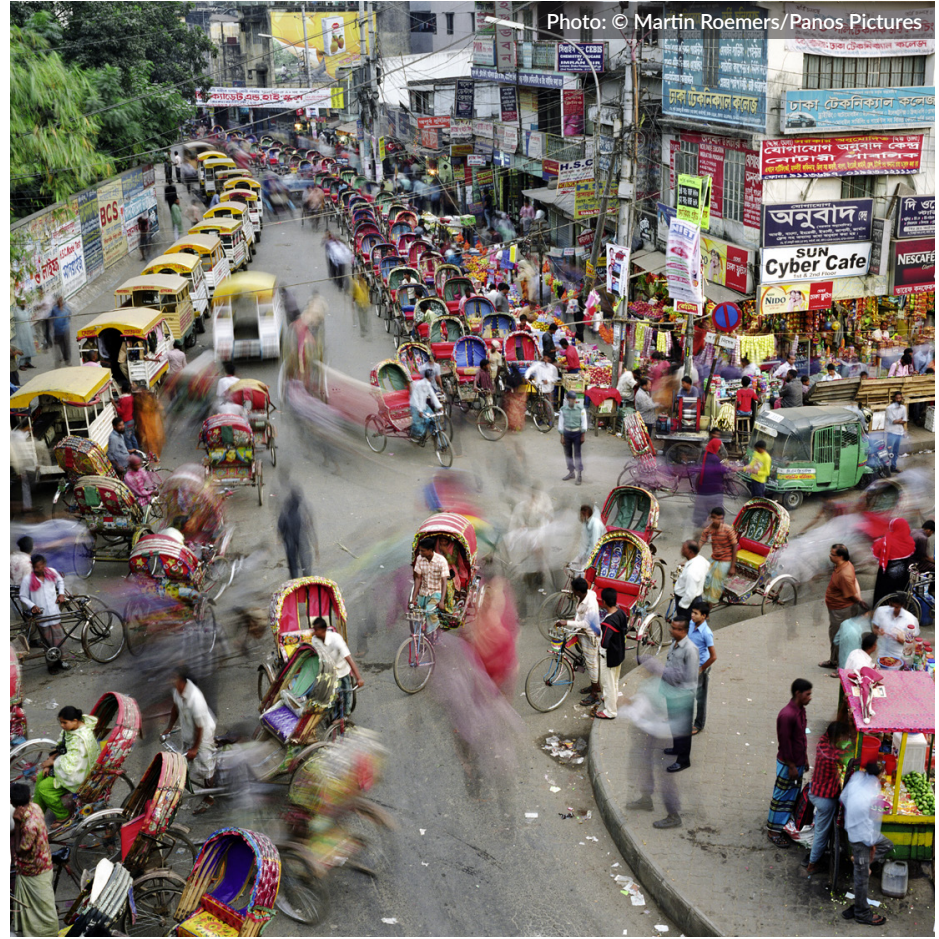

Rickshaws wait for customers as traffic drives by on a street in Dhaka, Bangladesh.

\section{Key messages}

- People's own coping strategies, and capacities to innovate and rely on the strength of local networks can contribute to sustainable, real-world solutions.

- Issues of wellbeing and a human security perspective on fragile conditions arise as central to making cities inclusive, safe, resilient and sustainable in times when migration and urbanisation processes are intensifying globally.

- Sport and cultural interventions that support youth-led dynamic networks of exchange are as relevant in addressing the challenges of inclusivity in rapidly growing urban contexts as the efforts to leverage direct governmental action at the local and national levels to directly enable access to urban services. 


\section{Building empathy for safe and sustainable cities}

While migration is pursued as a pathway out of poverty, lowincome migrants are often exposed to environmental hazards and face reduced access to urban services and labour markets. In policy circles, migrants are sometimes regarded as the source of problems and little has been done to explore their potential as a source of innovation in urban planning for sustainability.

Cities have the potential to pursue a trajectory towards improved sustainability by having legitimate and inclusive governance, which engages and integrates the needs and interests of urban populations, especially new migrant populations who face a unique set of challenges that require integrated solutions.

In an effort to explore a potential pathway to improved sustainability, the project engages with new urban populations in Chattogram, Bangladesh, and employs a variety of methods (survey, photovoice, photo elicitation, perspective-taking and policy workshops) to unpack the challenges migrants experience in urban centres in relation to sustainability, security, integration and wellbeing. When we ask migrants about their everyday experiences of wellbeing and human security in their urban destination, they recount high levels of happiness alongside frequent feelings of anxiety, worry, and hopelessness/depression, and talk about their concerns and insecurity relating to food, housing, income, and poor health.

These insights are integrated into a perspective-taking workshop to facilitate dialogue between Chattogram's migrant communities and representatives of local planning and development authorities. Powerful visual images captured by participants as part of the photovoice exercise can facilitate empathy between migrants and policy stakeholders, and lead to identifying priorities for policy and practice through photo-elicitation. The photographs can prompt sympathy among urban planners: 'When I saw these pictures of the city, I felt very sad for the people who are living there'.

During the workshop, migrants and urban planners elicit several pressing concerns, which not only affect their wellbeing but have important implications for meeting SDGs 11, 4, and 8. Building on these insights, work continues with policy stakeholders at local and national levels, to explore opportunities for integrating the research findings into emerging development initiatives (e.g. Chattogram urban development plan), and to enable and support collaboration between various policy/planning organisations and voluntary service providers (e.g. educational charities). Though local policy and urban planning authorities demonstrate political will and commitment to solving existing challenges, the policy workshop held in Chattogram revealed that these efforts are often hampered by existing top-down governance and associated bureaucratic red tape. Participants propose that for lasting and effective change systemic thinking and holistic solutions will be required, and a first step towards these should be improved communication and coordination between various planning and development authorities at different scales.

A number of lessons for policy and practice emerge. The variety and complexity of social, economic and environmental challenges affecting the everyday security and wellbeing of vulnerable migrant populations in urban centres are currently not well recognised or adequately addressed in existing policies of urban development. In fact, migrants are often regarded as the source of urban predicaments and their role in providing solutions is not sufficiently explored. However, recognising the perspectives and lived experiences of these new urban populations could lead to more effective, sustainable and legitimate solutions.

The research, therefore, could deliver benefits for a number of different stakeholders at different scales of development and governance. The principal beneficiaries are migrants, who experience high levels of poverty, recurrent adversity and sentiments of disempowerment in their urban destinations. They are empowered through the participatory empathy-building processes to share their lived experiences and to engage with planners and policymakers. It is hoped that disseminating these perspectives among policymakers and practitioners through workshops at the local and national levels will increase migrants' access to frontline services for health, hygiene, sanitation and clean drinking water. Other beneficiaries include Chattogram's city planners and Bangladeshi government agencies by gaining new insights into the lives of migrant populations. It is hoped that they will integrate these insights into their professional practice to develop interventions and policies that provide more effective and legitimate solutions to urban sustainability challenges.

Lessons that emerged are also relevant for development policy and practice more broadly: engaging migrant populations and policymakers in a dialogue offers a fresh angle on meeting global sustainable development goals and targets.

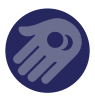

Project title: Safe and sustainable cities: human security, migration and wellbeing

\section{W. Neil Adger}

Professor of Human Geography

University of Exeter, UK

The study fostered partnership and collaboration between researchers at the Refugee and Migratory Movements Research Unit in Dhaka, Bangladesh (Tasneem Siddiqui, Mahmudol Hassan Rocky, Mohammed Rashed Alam Bhuiyan, Tamim Billah) and the University of Exeter, UK (Ricardo Safra de Campos, Lucy Faulkner and Lucy Szaboova).

SEE ALSO:

Banks, N.; Roy, M. and Hulme, D. (2011) 'Neglecting the Urban Poor in Bangladesh: Research, Policy and Action in the Context of Climate Change', Environment and Urbanization 23: 487-502

Lintelo, D.J.H. et al. (2018) 'Wellbeing and Urban Governance: Who Fails, Survives or Thrives in Informal Settlements in Bangladeshi Cities?', Cities 72.2017: 391-402.
Ortega-Alcázar, I. and Dck, I. (2011) 'Migrant Narratives of Health and Wellbeing: Challenging Othering Processes Through Photo-Elicitation Interviews', Critical Social Policy 32: 106-25

Rao, N. (2013) 'Migration, Mobility and Changing Power Relations: Aspirations and Praxis of Bangladeshi Migrants', Gender, Place and Culture 21: 872-88 


\section{Energy on the move: perspectives from the urban marginal}

Growing numbers of poor live in peri-urban informal settlements. In terms of UN 'Sustainable Energy for All', can they access clean and affordable energy? Research across four countries into people's real-world energy practices, coping strategies, resourcefulness and support networks reinvents how renewable technologies and policies can achieve inclusive energy transitions.

Energy poverty has a 'gendered face' is a key finding from this project that brought Durham University's research team from Anthropology, Geography and History together with investigators from Nigeria, South Sudan, Nepal and Bangladesh. The project aimed to develop the capacity for interdisciplinary research about energy practices among the poor by applying a 'socio-technical' approach to understand the role of energy in social change. Attending to historical and climateaffected patterns of urban settlement in these countries provides unique perspectives on the prospects for SDGs 7 and 11 - aiming for 'inclusive' transitions from biomass energy (such as fuelwood and charcoal) to modern, clean energy sources.

We sought out energy resilience narratives and energy life histories for insights into this globally important policy area: provision of clean energy to meet the needs of the urban poor. Technologists, engineers and economists normally dominate this domain using quantitative methods. Instead, we asked how people access fuels for cooking, lighting and heat, what were their preferred energy sources, what energy-related difficulties they faced due to living in informal settlements, and what was their knowledge and opinion of renewable energy technologies. In each country we engaged our findings with mixed consultative groups of policy, technology, NGO and grass-roots interests.

The country studies showed how problems of energy access for informal settlers reflect their lack of empowerment as citizens in urban public spheres. In the two African countries, charcoal is a preferred fuel of convenience. In South Sudan, interviewees stressed that the market in charcoal has grown rapidly over the last two decades and is controlled by militarised networks. In Nigeria, issues of ethnicity and land ownership affect fuel access. Women with husbands who ride motorbike taxis find better fuels in the urban economy. Mains grid electricity is unreliable, and does not supply camps of conflict migrants. As in Nepal and Bangladesh, where people mostly use gas to cook, access to grid electricity makes a difference to households, often via informal line extensions for which people pay more than twice the official rate.

Women directly manage fuel scarcities and coping strategies, due to cultural expectations of domestic life and in multi-tasking with microenterprises. The Nigerian research shows an association of cleaner fuels and solar with male domains, while women are still cooking in the manner of their great-grandmothers. Energy issues exemplify the marginalisation of women in national development debates discussed through Country Consultative Groups assembled in each country.

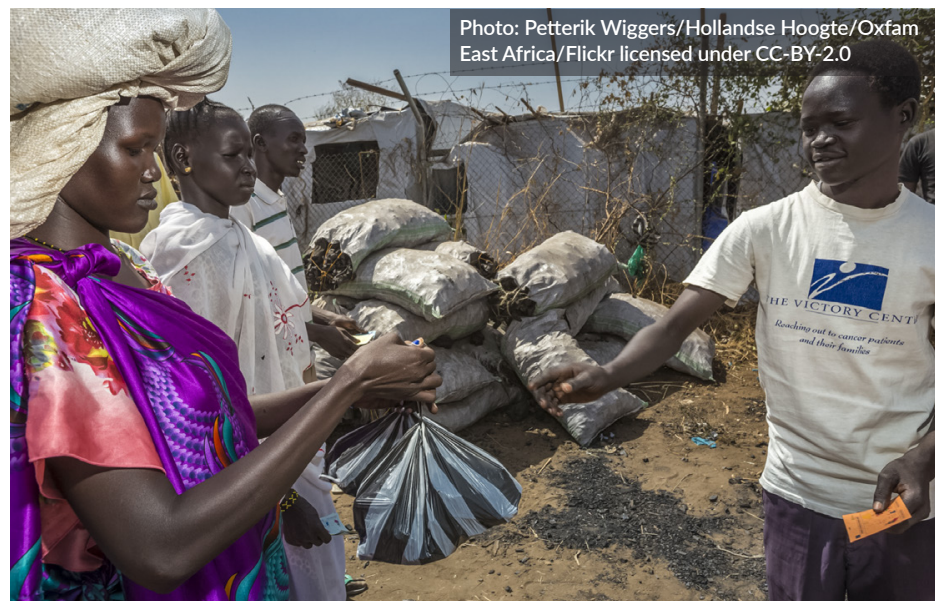

Oxfam charcoal voucher programme, South Sudan.

This research discovered very little use of renewable energy technologies among the informal settlers of the four countries. Reasons for this include cost and worries about theft of equipment, but also a lack of development priority attention to the condition of the increasing populations of informal settlers, and women in particular, by NGOs or municipal authorities.

Points of connection for developing initiatives to increase familiarity with, and applications for, solar devices and potentially biogas systems were revealed. These connections came from looking at energy practices with a gendered focus, finding men, women and youth coping and innovating. They seek resilient relationships for everyday survival, improvising social networks that interweave with forms of energy and the services they provide. The accounts of how different fuels figure in terms of convenience and accessibility can inform attention to the role of renewables in both temporary humanitarian contexts, and in emerging communities of peri-urban places that are seeking civic respect and rightful participation in projects of sustainable energy transition.

This research has shown how paying attention to sustainable energy needs among informal settlers in their gendered diversity provides a vital platform of evidence about capacities for innovation to plan for sustainable energy transitions. It can help improve the health of the next generation by reducing smoke inhalation, enabling children to study at night, bringing power to run appliances for education and productive uses, and facilitating the organisation of neighbourhood institutions to create better living environments and enhanced cooperation with municipal authorities.

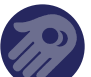

Project title: Energy on the move: Longitudinal perspectives on energy transitions among marginal populations (a comparative study)

\section{Dr Ben Campbell \\ Durham University}

This study took place in collaboration with Fatima Adamu, Technical Lead, Education for Women in Health, Global Health, DAI.

SEE ALSO:

Castan-Broto, V. et al. (2017) 'A Research Agenda for a People-Centred Approach to Energy Access in the Urbanizing Global South', Nature Energy 2: 776-79

Brown, E. et al. (2018) 'Low Carbon Energy and International Development: From Research Impact to Policymaking', Contemporary Social Science 13: 1, 112-127, doi:10.1 080/21582041.2017.1417627

Das, V. and Walton, M. (2015) 'Political Leadership and the Urban Poor Local Histories', Current Anthropology 56.11: 44-54

Anderson, T.; Shamsuddoha, Md and Dixi, A. (2016) 'Climate Change Knows No Borders. An Analysis of Climate Induced Migration, Protection Gaps and Need for Solidarity in South Asia', Action Aid and Climate Action Network South Asia 


\section{Investigating sustainable development: youth, sport and cultural interventions}

\begin{abstract}
The Sport for Development and Peace sector aims to use sport and culture to address sustainable development issues such as poverty and gender inequality. However, there is little unified knowledge from across low- and middle-income countries (LMICs) about how sport and cultural programmes are implemented, and how they are experienced by young people.
\end{abstract}

According to the 2030 Agenda for Sustainable Development, sport contributes to 'the realization of development and peace in its promotion of tolerance and respect... the empowerment of women and of young people, individuals and communities as well as... health, education and social inclusion objectives.' In response, researchers from Loughborough University, University of California, Berkeley, and Kathmandu University have investigated how sport, culture and education programmes tackle poverty, conflict in fragile states, environmental sustainability, and gender inequality in three LMICs Cape Verde, Nepal and Timor-Leste.

The project has three broad aims: (i) to enhance knowledge of sport, cultural and educational programmes in LMICs; (ii) to improve programme efficacy in policy and practice; and (iii) to work with key stakeholders to secure social change. The research draws on three primary research methods: a minimum of six weeks' fieldwork in each research location, approximately 120 interviews/focus group discussions with key stakeholders, and participatory action research that captures the voices of young people.

The comparative research highlights that grass-roots organisations across the three research sites are addressing Sustainable Development Goals (SDGs) related to equality and inclusivity, through youth-led programmes that integrate sport and the arts. In doing so, young people are developing new networks that cut across social and cultural divides. They are also fostering community resilience, as an interlinked network of cultural, financial, social, political and human resources, by harnessing urban areas such as community centres and unused outdoor spaces for youth education, training, and social integration.

In all three locations, the researchers have identified and worked with programmes seeking to tackle gender inequality. For example, trekking guide training for young women from across Nepal challenges male domination of this national field of employment and leisure, while also providing participants with economic and social capital.

Researchers also worked with programmes that use sport and creative industries to develop employability and entrepreneurial skills, and harness local educational models that centre on empathy and creativity. These interventions also act as a defence against the pull of foreign migration. Physical cultures (group sports, traditional dance, and Zumba) across all three research sites are enabling communities of practice to be built among marginalised groups such as women and
LGBTQIA+ people, and are providing a means to resolve community conflicts by bringing youths from different backgrounds together. The research is also helping to build up networks for organisational stakeholders across the sector at national and international levels, by providing the basis for new partnerships.

The research is having various impacts, at local, national and international levels. For instance, it is:

- Giving voice to young people by enabling them to pitch their programmes at local seminars, and at the end-of-project event. For example, one young facilitator from our partner NGO in TimorLeste pitched her programme for addressing gender inequality in sport, highlighting how she wished to extend inclusive sports events from the urban centre of Dili, where community resilience had been forged, to rural municipalities across the country.

- Influencing national sport and migration policies, by highlighting the issues faced by young athletes and migrant workers in developing contexts (economic exploitation; gender inequality; poor facilities).

- Contributing to various policy debates. For example, in relation to the need for network-building between environmental organisations, educational centres and nautical sports practitioners in Cape Verde, to raise awareness of the sea as a sustainable resource.

- Engaging with the President's advisor and the National Olympic Committee in Cape Verde to develop social entrepreneurship opportunities for youths, to combat poverty.

Across our three research sites, youths are developing dynamic networks, which incorporate sport and the arts, and seek to address SDGs, and the researchers continue to liaise with the participants. In the process, they are co-creating a holistic model of development, which recognises the crucial role that young people, physical cultures, empathy and creativity can play in sustainable development. These findings will contribute to developing policy recommendations that help to tackle youth poverty and social exclusion, and thus create more resilient, inclusive and safe cities. In this way, new development frontiers can emerge, as youths contribute more fully to reshaping development processes.

Project title: New development frontiers? The role of youth, sport and cultural interventions

\section{Professor Richard Giulianotti}

Professor of Sociology, School of Sport, Exercise and Health Sciences Loughborough University, UK

Other members of the research team: Dr Aoife Sadlier (Research Associate, School of Sport, Exercise and Health Sciences) and Dr James Esson (Co-investigator, Department of Geography) at Loughborough University, UK; and Dr Martha Saavedra (Co-investigator, Center for African Studies, Department of Political Science, University of California, Berkeley, USA) and Professor Sagar Sharma (Co-investigator, School of Arts, Department of Development Studies, Kathmandu University, Nepal).

\section{SEE ALSO:}

Beutler, I. (2008) 'Sport Serving Development and Peace: Achieving the Goals of the United Nations through Sport', Sport in Society 11.4: 359-69

Coalter, F. (2007) A Wider Social Role for Sport: Who's Keeping the Score? Abingdon, Oxford: Routledge

Collison H.; Darnell, S.; Giulianotti, R. and Howe, P.D. (eds) (2019) The Routledge Handbook of Sport for Development and Peace, London: Routledge
Collison, H.; Giulianotti, R.; Howe, P.D. and Darnell, S. (2016) 'The Methodological Dance: Critical Reflections on Conducting a Cross-Cultural Comparative Research Project on 'Sport for Development and Peace', Qualitative Research in Sport, Exercise and Health 8.5: 413-23

Giulianotti, R. (2011b) 'The Sport, Development and Peace Sector: A Model of Four Social Policy Domains', Journal of Social Policy 40.4: 757-76 


\section{Crime, livelihoods and urban poverty in Nigeria}

Property crime (i.e. theft and burglary) in sub-Saharan Africa can have a devastating impact on the livelihoods and life savings of residents living in low-income neighbourhoods, and also reflects the lack of livelihood opportunities for urban youth. Yet, the perceptions and experiences of crime are often under-researched, or misrepresented.

To better inform policy interventions about how to manage crime and its impact on livelihoods, researchers from University College London (UCL) and Ahmadu Bello University ( $A B U$ ) Zaria studied the interlinkages between crime, livelihoods and urban poverty in the city of Kaduna, Nigeria. The project focused on the patterns of property crime at the street level to understand the relationship between offenders and victims of crime.

The project used datasets from an environmental survey of 13,687 properties (and the streets on which they were located) and 3,293 responses to a crime victimisation survey plus 113 interviews with community respondents and 22 follow-up interviews with key interlocutors and members of the informal community-based security providers and members of the recognised security providers known as the civilian Joint Task Force (JTF); focus group discussions with two vigilante organisations; and multiple field visits, walkabouts and semi-structured interviews with eight property crime offenders.

The researchers found that variation in rates of property crimes across three of the districts studied is significantly linked to particular risk factors at the street level, most notably that those responsible for the majority of crimes live within the very neighbourhoods where the crimes took place.

Formal policing is under-resourced in Nigeria and community-based vigilante organisations have emerged in most neighbourhoods whose members turn into security patrollers at night. Although a 2016 law recognises the civilian JTF, there is minimal regulation or support for its activities in practice. However, it functions to assist constituted authorities such as the police by first gathering evidence to identify offenders. They then either defer formal arrests or other criminal justice responses by providing a critical interim step of restorative justice whenever possible, where 'dealing with crime' focuses on rehabilitation of offenders through the reconciliation with victims of crime and the wider community, often based on local knowledge, community dialogue, and granting youth offenders 'another chance'. If the crime is deemed too grave, offenders are taken to the police directly.

While the activities of all security providers in safeguarding communities against crimes were found to be effective across the board (and more efficient than the police), there were also complaints about human rights abuses and what is locally known as 'jungle justice' in some cases. Understanding the difference between the various local security providers has been crucial to offering policy recommendations about which practices were both just and effective forms of security provision and crime deterrence. The researchers

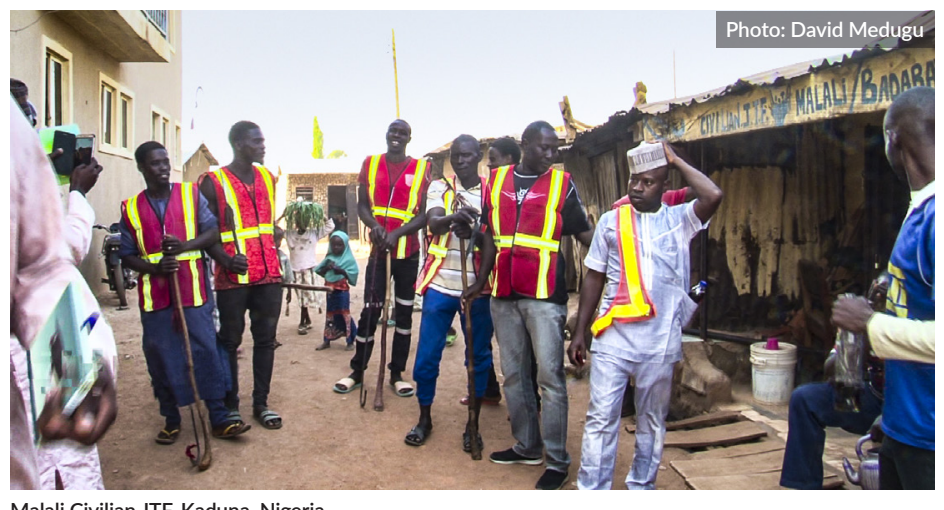

Malali Civilian JTF, Kaduna, Nigeria.

found that recent efforts to take certain individuals out of their local communities to create heterogeneous JTF units received significant pushback from local communities who preferred local security providers to be known residents within neighbourhoods who have understanding of local issues.

The research also documented local perceptions of what it takes to make a living in low-income and underserved neighbourhoods. Due to economic instability, a key livelihood strategy is for people to top up their primary source of income. Interviews with offenders - young males in their 20s - revealed that while their main prospect for employment is manual labour, they hardly get hired and are left with few other options, and property crime therefore becomes not so much an act of urban deviance as part of a portfolio of income generating activities to make a living against the odds.

The researchers concluded that the risks associated with contemporary urban life in a Nigerian city includes not only being a victim of crime, but also being pushed into crime as a form of last resort livelihood diversification strategy. They argue that patterns of petty street crime are inextricably linked to economic opportunities (or lack of) and the rapid changes in familial and traditional institutional networks.

As certain groups increasingly gain local recognition for their vital support in not only improving perceptions of safety in community settings, but also in some cases counselling youth offenders, this research offered ground-breaking opportunities to impact policies at the nexus of crime prevention, expanded opportunities for youth livelihood creation, and poverty alleviation.

Project title: Development frontiers in crime, livelihoods and urban poverty in Nigeria (FCLP)

\section{James A. Cheshire}

University College London

This is a collaborative research between researchers at University College London, UK (James Cheshire, Tatiana Thieme and Anwar Musah) and Ahmadu Bello University Zaria, Nigeria (Adamu Ahmed, Faisal Umar, Babagana Abdullahi, Khadija Yakubu and Muktar Ahmed).

\section{SEE ALSO:}

Musah, A. et al. (2019) 'Assessing the Impacts of Various Street-Level Characteristics on the Burden of Urban Crime in Kaduna, Nigeria', Journal of Applied Geography (Under review)

Umar, F.; Johnson, S.D. and Cheshire, J.A. (2018) 'Testing Theories of Social Disorganization in Nigeria', in G. Bruinsma and S.D. Johnson (eds), Oxford Handbook of Environmental Criminology, New York NY: Oxford University Press: 366-82
Theime, T.A. (2017) 'The Hustle Economy: Informality, Uncertainty and the Geographies of Getting By', Progress in Human Geography 42.4: https://doi. org/10.1177/0309132517690039

UN-Habitat (2007) Enhancing Urban Safety and Security: Global Report on Human Settlements, www.un.org/ruleoflaw/files/urbansafetyandsecurity.pdf 


\section{THE IMPACT INITIATIVE}

For International Development Research

This summary highlights the key messages from research focusing on urban community resilience from the ESRC-DFID Joint Fund for Poverty Alleviation and is an output of the Impact Initiative for International Development Research.

It is written in collaboration with research teams and edited by Kelly Shephard, Head of Knowledge Impact and Policy at the Institute of Development Studies (IDS). The academic reviewer for this paper was Dr Jaideep Gupte, Research Fellow, Cities Cluster, IDS.

The Impact Initiative seeks to connect policymakers and practitioners with the world-class social science research supported by the ESRC-DFID Strategic Partnership, maximising the uptake and impact of research from: (i) the Joint Fund for Poverty Alleviation Research; and (ii) the Raising Learning Outcomes in Education Systems Research Programme. We seek to identify synergies between these programmes and their grant holders, support them to exploit influencing and engagement opportunities, and facilitate mutual learning. The Impact Initiative is a collaboration between the Institute of Development Studies and the University of Cambridge's Research for Equitable Access and Learning (REAL) Centre.

Email: info@theimpactinitiative.net

Website: www.theimpactinitiative.net

y @the_Impact_Init \#impactlessons

All content is available under the Open Government License v3.0, except where otherwise stated

Joint Fund for Poverty Alleviation: aims to enhance the quality and impact of social science research, addressing the key international development goal of reducing poverty amongst the poorest countries and peoples of the world.

Raising Learning Outcomes in Education Systems Programme: aims to provide policymakers and practitioners with concrete ideas on how to improve

learning outcomes and to inform relevant policy and programme decision.

$\mathrm{E} \cdot \mathrm{S} \cdot \mathrm{R} \cdot \mathrm{C}$ ECONOMIC \& SOCIAL RESEARCH C OUNCI L

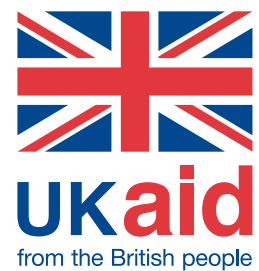

from the British people 